IETE Journal of Research

\title{
An Expert System for LD Steel Making
}

\section{P N Mishra, S K Kak \& S C Srivastava}

To cite this article: P N Mishra, S K Kak \& S C Srivastava (2001) An Expert System for LD Steel Making, IETE Journal of Research, 47:1-2, 85-89, DOI: 10.1080/03772063.2001.11416207

To link to this article: https://doi.org/10.1080/03772063.2001.11416207

\section{曲 Published online: 26 Mar 2015.}

Submit your article to this journal

\section{山 Article views: 7}




\title{
An Expert System for LD Steel Making
}

\author{
P N MISHRA \\ Instrumentation \& Electronics, National Metallurgical Laboratory, Jamshedpur 831 007, India.
}

$S$ K KAK

Electronics Engineering Department, Institute of Technology, Banaras Hindu University, Varanasi 221 005, India.

AND

S C SRIVASTAVA

ANC Division, National Metallurgical Laboratory, Jamshedpur 831 007, India.

\begin{abstract}
LD process of stealmaking accounts for $70 \%$ of steel production throughout the world. Due to various constraints like the complexity of LD process; variation in quantity, quality and grade of input materials; varying operating conditions, random parameters and their values; the interventions of an expert and skilled operator is necessary to tackle the complex situation. To overcome this, there exists, a need of a system, which does not only possess the process control capabilities, but also emulates operator's expertise in terms of his knowledge and skill. Such a system has been developed named "Expert Steelmaker". The paper discusses the "Expert Steelmaker" which can presently be used in an advisory mode by the LD steelmaking operator.
\end{abstract}

\section{Indexing terms: Expert system, LD steelmaking, Process control, Charge calculations, Materials} and energy balance.

$\mathrm{L}$ D process of steelmaking accounts for $70 \%$ of steel production throughout the world. Due to various constraints like the complexity of LD process; variation in quantity, quality \& grade of input materials; varying operating conditions, random parameters \& their values; the interventions of an expert and skilled operator is necessary to tackle the complex situation. To overcome this, there exists a need of a system which does not only posses the process control capabilities as discussed else where [1] but also emulates operator's expertise in terms of his knowledge and skill. We have developed such a system, named "Expert Steelmaker". No expert system tools have been used for building our "Expert Steelmaker" but, it has been developed using Prolog language only.

A few other expert systems for LD steelmaking have been reported in the literature. One such system is LD-ES which was built using an expert system support tool named FACOMESHELL [2]. The ESHELL runs on UTILISP, a dialect of LISP. It uses fuzzy logic for some of its knowledge representation. Another expert system combined with a mathematical model for BOF process control has been reported by $\mathrm{T}$ Yoshida et al [3]. This system applies a rule based reasoning technique to improve the output of presently available mathematical models and uses fuzzy reasoning to estimate in furnace reactions: Further, using an expert system, a one man operation of blowing has been established [4].

Paper No 164-A; Copyright $\odot 2001$ by the IETE.
Since engineering problem solving is not entirely symbolic and sophisticated numerical computation need to be performed to determine physical system parameters, a knowledge based system in that problem solving environment needs to be integrated with computational procedures for successful application. Sunderam et al [5] has proposed organisation of numeric computation using a task structure vocabulary and demonstrated its potential as a viable tool for integration of numerical methods with knowledge based systems. However, our prolog based ES does the computation as well as symbolic processing.

The paper discusses the "Expert Steelmaker" which can presently be used in an advisory mode by the LD steelmaking operator.

\section{TOWARDS BUILDING AN EXPERT COMPUTER SYSTEM}

The most important step in building such a system is knowledge acquisition followed by its representation for machine use and Interpretation. After building knowledge base, inference engine and user Interface are created so that inferences are drawn and made available to the outside user.

The first step in acquiring the process knowledge is the identification of an expert or group of experts. It has been pointed out by Mittal and Dyn [6] that multiple expert consultation is beneficial than basing the system on the knowledge of a single expert; further the expert should be 
always a practicing one. We also arrived at the same conclusion independently and have, therefore, chosen multiple experts for the codification of knowledge to be used by our system. These experts have been working in industry, in the area of LD steelmaking for more than a decade. Also, these persons are considered as experts by their colleagues.

Various expert operators of leading steel plants of India have been interviewed in various phases to acquire the operational knowledge; these, however; showed area of commonality and some regions of conflict in their expertise which had then to be resolved by crosschecking and observing the process.

The knowledge thus acquired had to be suitability represented with the help of a high level computer language. The evolution of certain high level languages for Artificial Intelligence has resulted in standard languages like LISP, ADA, PROLOG etc. IBM PC compatible turbo-Prolog has been used by us for the development of our expert system. It has been earlier demonstrated by Veronica Dahl [7] that logic programming can be used as a representation of knowledge for both database knowledge as well as procedural knowledge.

In the development process of this expert system we have used the knowledge available in the references $[8,9]$ extensively in addition to the knowledge elicited from experts from iron and steel industry. Modular programming has been used for realizing the expert system. An important feature introduced is a timer module that runs in background so as to remind the operator about different actions to be taken during a particular heat cycle.

\section{The aim and scope of "Expert Steelmaker"}

The aim of designing this Expert Steelmaker was to develop an adviser to an operator for complete heat cycle of an LD furnace. It has to achieve the following:

(a) To calculate the amount of materials needed to make a desired quality and quantity of steel. These materials are hot metal, steelscrap, burnt lime, burnt dolomite, oxygen etc.

(b) To optimize the process under various defined constraints and

(c) To guide the operator through the complete heat cycle specifying actions to be taken in response to feedback given interactively by the operators.

Our approach to achieve these aims is through knowledge based reasoning, dynamic process modeling and interactive operator's response evaluation. Rules have been formulated on the basis of knowledge acquired from experts and existing literature on LD stcelmaking. The declarative and procedural knowledge thus obtained have both been represented in Prolog.
Blow control strategies for LD process control have widely been used throughout the world, where in, blowing control is dependent on the operator's observation of the process. If the heat becomes too wild and sloppy, appropriate action is taken on the lance height or oxygen blowing rate. Sometime materials additions are also done. We have adopted a similar strategy in our expert system.

Various methods for automatic blowing control of BOF using computers have been employed since 1960 . These control methods are classified into two types:

(a) Static control in which the necessary amount of oxygen and that of the coolant are fixed before blowing by statistical or theoretical analysis of data on mass balance and heat balance.

(b) Semi dynamic control in which the carbon content in the molten steel is estimated and controlled to the aim value by analysis and information derived from the exhaust gas. However, the controllability of these methods is limited and not always satisfactory in achieving the composition and temperature at the end of blowing. A combination of static control and dynamic control have been proposed earlier $[10,11]$. Optimal control for LD converter process have also been reported [12]. Even then operator is a necessary element in controlling the process.

Our system with static control coupled with blow control strategy in the form of knowledge base (KB) evolves into an optimal dynamic control for the LD process of steelmaking.

\section{KNOWLEDGE BASED CHARGE CALCULATION}

The knowledge based charge calculation module is the heart of the Expert Steelmaker. It accepts input parameters in the following syntactical format using standard notation of elements and compounds to be provided by the operator of the LD furnace.

Composition of hot metal: $\mathrm{Al} \%, \mathrm{C} \%, \mathrm{Fe} \%, \mathrm{Mn} \%, \mathrm{P} \%$, S\%, Si \%, other \%,

Composition of steel scrap Al \%, C \%, Fe\%, Mn \%, P \%, $\mathrm{S} \%, \mathrm{Si} \%$, other $\%$.

Composition of gray iron: $\mathrm{Al} \%, \mathrm{C} \%, \mathrm{Fe} \%, \mathrm{Mn} \%, \mathrm{P} \%$, $\mathrm{S} \%, \mathrm{Si} \%$, other $\%$.

Composition of silicon carbide: $\mathrm{SiC} \%, \mathrm{SiO}_{2} \%, \mathrm{Al}_{2} \mathrm{O}_{3} \%$, other $\%$.

Composition of calcium carbide: $\mathrm{CaC}_{2} \%, \mathrm{CaS} \%$, $\mathrm{CaO} \%$ other $\%$.

Composition of iron ore: $\mathrm{CaO} \%, \mathrm{FeO} \%, \mathrm{Fe}_{2} \mathrm{O}_{3} \%, \mathrm{MgO}$ $\%, \mathrm{MnO} \%, \mathrm{P}_{2} \mathrm{O}_{5} \%, \mathrm{SiO}_{2} \%, \mathrm{Al}_{2} \mathrm{O}_{3} \%$, other \%. 
Composition of ferro-silicon: $\mathrm{SiC} \%, \mathrm{Fe} \%$, other $\%$.

Composition of burnt lime: $\mathrm{CaO} \%, \mathrm{MgO} \%, \mathrm{SiO}_{2}$, $\mathrm{Fe}_{2} \mathrm{O}_{3} \%, \mathrm{Al}_{2} \mathrm{O}_{3} \%$, other \%, LOI \%.

Composition of burnt dolomite: $\mathrm{CaO} \%, \mathrm{MgO} \%, \mathrm{SiO}_{2} \%$, $\mathrm{Fe}_{2} \mathrm{O}_{3} \%, \mathrm{Al}_{2} \mathrm{O}_{3} \%$, other $\%$, LOI.

Composition of steel to be made $\mathrm{C} \%, \mathrm{O} \%$.

Tonnage oxygen $\mathrm{O}_{2} \%$, by volume, $\mathrm{N}_{2}$ plus Ar \%, by volume.

Element distribution (\% of weight charged):

$\%$ of $\mathrm{C}$ oxidized to $\mathrm{CO}, \%$ of $\mathrm{C}$ oxidized to $\mathrm{CO}_{2}$.

$\%$ of total $\mathrm{Mn}$ to steel, \% of total $\mathrm{Mn}$ to slag.

$\%$ of total P to steel, \% of total P to slag.

$\%$ of total S to steel, \% of total S to slag.

$\%$ of total $\mathrm{Fe}$ oxidized to $\mathrm{Fe}_{2} \mathrm{O}_{2}$ fume.

Composition of slag (weight ratios) $-\mathrm{CaO} / \mathrm{SiO}_{2}, \mathrm{MgO} /$ $\mathrm{SiO}_{2}, \mathrm{Fe}_{2} \mathrm{O}_{3} / \mathrm{SiO}_{2}$.

The output information provided by the charge modules are:

- weight of hot metal,

- weight of steelscrap (or any two combination of materials like hotmetal, steelscrap, gray iron, ferrosilicon, silicon carbide and calcium carbide),

- weight of burnt lime to be added,

- weight of burnt dolomite to be added, and

- weight of tonnage oxygen to be blown

for a ton of steel of desired composition at the desired temperature.

This module works in conjunction with the knowledge base such that if the desired composition of steel to be made is known in terms of grade of steel to be made, it automatically assumes the composition of steel to be made. Additionally, KB has a range of values for all input informations. Whenever, the operator exceeds the limit of the range for an input, while inputting the informations, the system prompts him to recheck. If the operator confirms, $\mathrm{KB}$ will update the range of the corresponding input information for future use, giving it learning capability. Otherwise it understands it as a mistake and asks the operator to re-enter the correct value. If the operator is ignorant about the particular input information's value, the knowledge module assume the value based on its latest knowledge of that information.

The charge calculation module has a grade sub module which stores all the composition range for different grades of steel, which are most often produced by a particular steel plant. However, this sub module can be updated for any new type of grade of steel to be produced by dynamically interacting with the knowledge module.

\section{GUIDANCE AND EXPLANATION FOR THE OPERATOR}

The expert system (ES) guides the operator of LD furnace through the complete process cycle after outputting the quantity of materials required for the desired heat. It is an interactive process, in the sense that the expert system advises the action to be taken by the operator, waits for his response and then goes to the next action. After estimated time of oxygen blow, it tells that heat is ready to be tapped.

Basic explanation capabilities like answers to what and why type of questions have also been incorporated into the system to make it user friendly. An example is given below:

$\begin{array}{ll}\text { Operator } & \text { What (softblow) } \\ \text { ES } & \begin{array}{l}\text { Softblow means keep lance height at more } \\ \text { than } 2.5 \mathrm{~m}\end{array} \\ \text { Operator } & \text { Why (softblow) } \\ \text { ES } & \text { Softblow because dc-dt is between } 48-60 .\end{array}$

\section{RESULTS AND DISCUSSION}

To validate and test the charge calculation module, material and energy balance for a few typical cases have been undertaken using data samples from ref [8]. The results are in agreement with the corresponding material and energy values [8] and are given in Table 1. Charge calculation also seem to be reasonable though they have not been practically verified. The response of ES to various input conditions have been evaluated and found satisfactory.

\section{CONCLUSION}

An advisory expert system has been developed for LD process steel making which undertakes charge calculation intelligently and guides interactively the operator of LD process for a complete cycle till the heat is ready to be tapped. The system does not use any ES shell and is implemented using Prolog language which has been used for representing declarative and procedural knowledge: timing and mathematical calculation. The system should be quite useful for the Steel Industry. Similar technique may be used in other advisory mode process control application where material and energy balance are important and operator interaction with the process is a necessity. By providing suitable hardware and software interface, the system can be used for on line process control application also. 
TABLE 1 Material balance and heat effect at selected temperatures for six cases

\begin{tabular}{|c|c|c|c|c|c|}
\hline \multicolumn{3}{|c|}{ Case-I } & \multicolumn{3}{|c|}{ Case-IV } \\
\hline & $\begin{array}{c}\text { Values as per } \\
\text { Ref. (8) } \\
(\mathrm{kg})\end{array}$ & $\begin{array}{l}\text { Values as per } \\
\text { our expert } \\
\text { system } \\
(\mathrm{kg})\end{array}$ & & $\begin{array}{l}\text { Values as per } \\
\text { Ref. (8) } \\
(\mathrm{kg})\end{array}$ & $\begin{array}{l}\text { Values as per } \\
\text { our expert } \\
\text { system } \\
(\mathrm{kg})\end{array}$ \\
\hline INPUT ITEMS & & & INPUT ITEMS & & \\
\hline Hot metal & 1000 & 1000 & Steel Crap & 1000 & 1000 \\
\hline Burnt lime & 63 & 63 & Burnt lime & 0 & 0 \\
\hline Burnt dolomite & 20 & 19.6 & Burnt dolomite & 0 & 0 \\
\hline $99.5 \%$ Oxygen & 86 & 85.6 & $99.5 \%$ Oxygen & 3 & 3.36 \\
\hline TOTAL INPUT & 1169 & 1168.2 & TOTAL INPUT & 1003 & 1003.36 \\
\hline OUTPUT ITEMS & & & OUTPUT ITEMS & & \\
\hline Steel & 912 & 912.1 & Steel & 981 & 981 \\
\hline Slag & 141 & 140.49 & Slag & 13 & 13.3 \\
\hline Gas \& Fume & 116 & 115.56 & Gas \& Fume & 9 & 8.69 \\
\hline TOTAL OUTPUT & 1169 & 1168.15 & TOTAL OUTPUT & 1003 & 1002.99 \\
\hline Heat effect & $-131 \mathrm{MCal}$ & $-132 \mathrm{MCal}$ & Heat effect & $315 \mathrm{MCal}$ & $315 \mathrm{MCal}$ \\
\hline & Case-II & & & Case-V & \\
\hline & $(\mathrm{kg})$ & $(\mathrm{kg})$ & & $(\mathrm{kg})$ & $(\mathrm{kg})$ \\
\hline INPUT ITEMS & & & INPUT ITEMS & & \\
\hline Gray Iron Scrap & 1000 & 1000 & Iron Ore & 1000 & 1000 \\
\hline Burnt lime & 158 & 157.5 & Burnt lime & 149 & 149.1 \\
\hline Burnt dolomite & 49 & 49 & Burnt dolomite & 33 & 33.38 \\
\hline $99.5 \%$ Oxygen & 92 & 91.92 & $99.5 \%$ Oxygen & -265 & -265.2 \\
\hline TOTAL INPUT & 1299 & 1298.42 & TOTAL INPUT & 917 & 917.28 \\
\hline OUTPUT ITEMS & & & OUTPUT ITEMS & & \\
\hline Steel & 877 & 876.6 & Steel & 599 & 599.3 \\
\hline Slag & 340 & 339.5 & Slag & 313 & 312.9 \\
\hline Gas \& Fume & 82 & 82.1 & Gas \& Fume & 5 & 4.8 \\
\hline TOTAL OUTPUT & 1299 & 1298.2 & TOTAL OUTPUT & 917 & 917 \\
\hline Heat effect & $122 \mathrm{MCal}$ & $120.5 \mathrm{MCal}$ & Heat effect & $148 \mathrm{MCal}$ & $148 \mathrm{MCal}$ \\
\hline & Case-III & & & Case-VI & \\
\hline & $(\mathrm{kg})$ & $(\mathrm{kg})$ & & $(\mathrm{kg})$ & $(\mathrm{kg})$ \\
\hline INPUT ITEMS & & & INPUT ITEMS & & \\
\hline Calcium carbide & 1000 & 1000 & Silicon carbide & 1000 & 1000 \\
\hline Burnt lime & -937 & -936.5 & Burnt lime & 5298 & 5297.9 \\
\hline Burnt dolomite & 12 & 12.1 & Burnt dolomite & 1648 & 1648.5 \\
\hline $99.5 \%$ Oxygen & 655 & 656.19 & 99.5\% Oxygen & 1900 & 1900 \\
\hline TOTAL INPUT & 730 & 731.79 & TOTAL INPUT & 9846 & 9846.4 \\
\hline OUTPUT ITEMS & & & OUTPUT ITEMS & & \\
\hline Steel & 14 & 14 & Steel & -2081 & -2081 \\
\hline Slag & -32 & -31.6 & Slag & 11070 & 11072 \\
\hline Gas \& Fume & 748 & $748 . \dot{3}$ & Gas \& Fume & 857 & 857 \\
\hline TOTAL OUTPUT & 730 & 730.7 & TOTAL OUTPUT & 9846 & 9848 \\
\hline Heat effect & $-232 \mathrm{MCal}$ & $-230 \mathrm{MCal}$ & Heat effect & $-242 \mathrm{MCal}$ & $-380 \mathrm{MCal}$ \\
\hline
\end{tabular}




\section{REFERENCES}

1. S N Singh, P N Mishra \& L N Das, PC based process control instrumentation, CSIO Communication, India, vol 16 , nos 1-4, pp 91-101, 1989.

2. Michitaka Kanemoto et al, An application of expert system to LD converter process, ISIJ International, vol 30, no 2, pp 128-135, 1990.

3. T Yoshida et al, A hybrid expert system combined with a mathematical model for BOF process control, Proc of IFAC workshop, Espoo, Finland, 26-28 August, 1991, (Oxford UK Pergamon, 1992) pp 51-56.

4. T Hatamaka et al, Development of blowing control system in BOF applying AI technology, Proc of IECON, 91, Kobe, Japan, 28 October-November 1991.

5. A Sunderam, J K McDowell \& M C Howley, Task structure: a vocabulary for integrating numerical methods and knowledge based systems, Math Comput Simul (Netherlands), vol 36, nos 4-6, pp 337-346, October 1994.

6. Mittal S \& Dyn C L, Knowledge acquisition from multiple experts, Al Magazine, vol 6, pp 32-36, Summer, 1985.
7. Veronica Dahl, Logic programming as representation of Knowledge, IEEE Computer, vol 16, no 10, pp 106-111, October 1983.

8. R D Pehlke, W F Porter, R F Urban \& J M Gaines (Ed). BOF steelmaking, (vol 4 Operation). The Iron and Steel Society of the American Institute of Mining, Metallurgical, Petroleum Engineers, 1977.

9. Turbo prolog, Owners handbook 1.1, Borland International, USA, 1986.

10. T Yamazaki et al, Development of the automatic blowing control system, Proc The International Oxygen Steelmaking Congress, Linz Austria, May 25-29, pp 509502, 1987.

11. L Coutinho Neto et al, Static control at CSN's Steelmaking. shop, Proc The International Oxygen Steelmaking Congress, Linz, Austria, pp 569-575, May 25-29, 1987.

12. Shigeru Hirohama et al, Application of optimal control theory to LD converter process control, Nippon Steel Technical Report No 27, October 1985.

\section{AUTHOR}

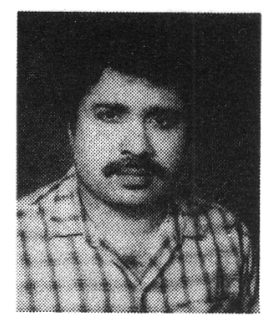

P N Mishra did his MSc (Tech) in Instrumentation from BITS, Pilani. After working as Instrumentation Engineer at BASL, Patratu (1976), Physicist at Research \& Control Laboratory, Durgapur Steel Plant, SAlL (1977-1981), and Electronics Engineer at Tata Steel, Jamshedpur (1981-1988), he joined as Scientist at National Metalurgical Laboratory, Jamshedpur, where he is presently Head of Instrumentation \& Electronics Division. His present research interest is in instrumentation, expert system and XRF. 